\title{
Large Hiatal Hernia Associated with Cameron Ulcers and Consecutive Sideropenic Anemia: Case Presentation
}

\author{
Zaim Gashi $^{1}$, Arjeta Gashi ${ }^{2}$, Fadil Sherifi ${ }^{3 *}$ (D) Fitore Komoni $^{3}$ \\ ${ }^{1}$ Clinic of Gastroenterology with Hepatology, UBT College, UCCK, Prishtina, Kosovo; ${ }^{2}$ Institute of Pharmacology, UCCK, \\ Prishtina, Kosovo; ${ }^{3}$ Department of Internal Medicine, Clinic of Gastroenterology with Hepatology, UCCK, Prishtina, Kosovo
}

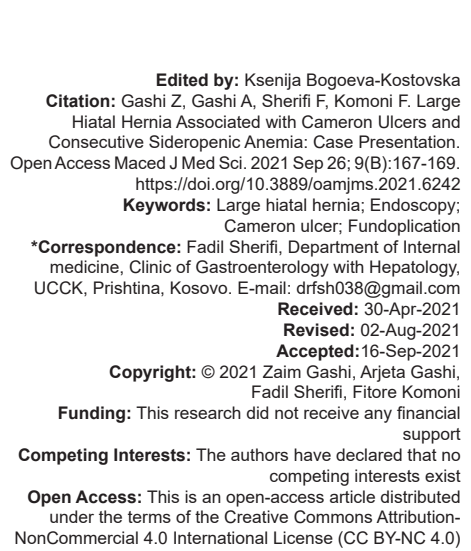

\section{Introduction}

Cameron lesions are seen in $5.2 \%$ of patients with hiatal hernia during esophagogastroduodenoscopy (EGD). Cameron lesions present clinically, mostly with chronic gastrointestinal (GI) bleeding and are associated with iron deficiency anemia. But, can also present as acute upper GI bleeding, occasionally lifethreatening, in up to one-third of cases [1]. Cameron lesions are linear gastric ulcers or erosions in the folds of the gastric mucosa at the level of the diaphragm in patients with large hiatal hernia [2].

Hiatal hernia can be clinically presented as a bimodal form, an accidental asymptomatic finding but may be associated with gastroesophageal reflux disease and Cameron ulcer in association with large hiatal hernias [2], [3]. The etiology is believed to be that of small erosions at the waist of the hernia which bleed slowly [4].

Mechanical trauma, ischemia, and acid mucosal injury may play a role in the pathogenesis of Cameron lesions [4]. The incidence of Cameron ulcer depends on the size of the hiatal hernia and increases in proportion to the size of the hernia.
The larger hernias $(>3 \mathrm{~cm}$ ) are associated more frequently with iron deficiency anemia than small hernias $(<3 \mathrm{~cm}$ ) [5]. Endoscopy is the gold standard for diagnosis, although it is not uncommon to overlook these lesions due to their unique location. They are often missed on the initial endoscopy and are usually discovered on subsequent endoscopies [6].

\section{Objective}

The aim of this case report is to present the patient with Cameron ulcers associated with hiatal hernia.

\section{Case Report}

We present the case, a 65-year-old woman, with postprandial retrosternal pain, especially immediately after eating, vomiting, dyspnea, weight loss, fatigue, signs, and symptoms of severe hypochromic microcytic 
anemia without signs of acute GI bleeding and with no obvious cause of chronic blood loss, but with some short time episode of dark brown stool in the past. The patient had a history of long-term symptoms of $>10$ years and treatment with antisecretory drugs, mostly proton pump inhibitors (PPI). She had a cholecystectomy 10 years ago.

In the Emergency Room, blood pressure was $110 / 70 \mathrm{mmHg}$, heart rate of 108 beats per minute, respiratory rate of 25 breaths per minute, and oxygen satutarion $95 \%$ at room air. On physical examination, she appeared pale, not in acute distress, with clear and bilaterally equal breath sounds and normal heart sounds, but with slight systolic ejection murmur in all auscultation points (Levine 1/6). Her abdomen was soft and not tender, without any organomegaly. Digital rectal examination did not reveal dark brown stool. From laboratory tests, there were low hemoglobin $95 \mathrm{~g} / \mathrm{L}$ and iron serum value $5.9 \mathrm{mmol} / \mathrm{L}$. Renal function, platelet, and white blood cell counts were normal. Prothrombin time, international normalized ratio, and activated partial thromboplastin time values were normal. Aspartate aminotransferase and alanine aminotransferase levels were also normal. This was the first hospitalization in our clinic for gastroenterology and hepathology complaint. The endoscopy showed a large hiatal hernia (more $5 \mathrm{~cm}$ ) and linear erosions/ ulcerations at the level of gastrodiaphragmatic contact (Cameron ulcers) and one non-sanguinant subcardial elipsoid ulceration.

The case was treated ambulantory for a long time with PPI and time to time with oral iron supplementation, with slight intermittent improvement. After the endoscopic examination due to severe refractory anemia and large hiatal hernia, associated with clinical signs, surgical approach was self-treatment modality and the fundoplication was done. For further follow-up, barium radiological examination is provided, and after 6 months in EGD, there were no signs of ulcers.

In Figure 1, endoscopy showed mucosal erythema, edema, and linear ulcers-Cameron lesions in the gastric mucosal folds.

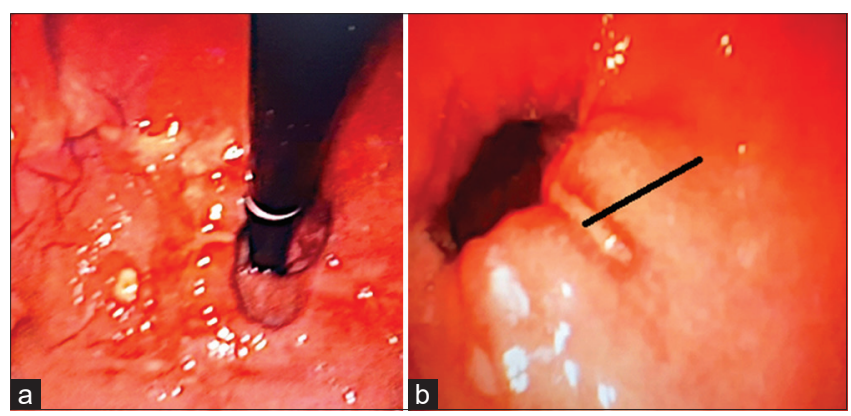

Figure 1: (a and b) View of Cameron's ulcers on endoscopy

\section{Discussion}

In a study by Camus et al. of 3960 endoscopies, Cameron lesions were found only in $0.6 \%$ cases [7]. Their prevalence increases with the size of the hiatal hernia. The hiatal hernia in our case was large. Among obscure $\mathrm{Gl}$ bleeders the prevalence is around 3.8\% [8]. We presented the case, a 65-year-old woman, with postprandial retrosternal pain, especially immediately after eating, vomiting, dyspnea, weight loss, fatigue, signs and symptoms of severe hypochromic microcytic anemia without signs of acute Gl bleeding.

GI bleeding accounts for 350/100,000 hospitalizations annually in the United States. Of these, $50 \%$ are due to upper $\mathrm{Gl}$ hemorrhage. The common causes of upper GI bleed in descending order of occurrence are peptic ulcer (38\%), esophageal or gastric varices $(16 \%)$, esophagitis $(13 \%)$, upper GI tract tumor $(7 \%)$, angioectasia $(6 \%)$, Mallory-Weiss tear $(4 \%)$, erosions $(2 \%)$ and Dieulafoy's lesion $(2 \%)$. The cause is unknown in $8 \%$ of the cases [9]. Cameron lesions have a range of manifestations from asymptomatic presentation of an occult GI bleed causing iron deficiency anemia to life-threatening overt GI bleeding [3]. Rate of occurrence of overt GI bleed was rare in the study done by Cameron. Presentations were mainly chronic anemia [2]. In subsequent studies, the rate of overt GI bleeding has been reported with increasing frequency. In the study done by Weston, the following presentations were seen in descending order of occurrence: Acute upper GI bleeding (32\%), dysphagia (17.8\%), reflux disease symptoms (10.7\%), and chronic GI bleeding (8.9\%). It was an incidental finding in $51.8 \%$ cases [2]. Camus et al. reported a presence of overt GI bleeding in the form of melena, hematemesis, hematochezia in $64 \%$ cases and occult GI bleeding in $36 \%$ cases [8]. In our case, the manifestation was overt GI bleeding.

Mechanical trauma has been proposed by numerous authors as being the most likely cause of the formation of the Cameron lesion [2]. It was proposed that the lesions were caused by mechanical trauma at the level of constriction by the diaphragm [9]. Gray et al. suggested that if the Cameron lesion were the result of solely mechanical forces, then the only viable treatment would be surgical [7]. However, the excellent response of this lesion to medical management with oral acid suppressants leads to the postulation of the co-existence of non-mechanical pathophysiological factors such as gastric acid injury [1]. Other proposed mechanisms are focal ischemia due to diaphragmatic pressure on the herniated sac (Moskovitz), gastric stasis from poor emptying of the pouch, venous outflow, and lymphatic obstruction resulting in vascular stasis and edema [2].

Medical management of our patient consisted with iron supplementation and proton pomp inhibitors. Otherwise, surgical treatment is realized 
with fundoplication. There are two modalities for the treatment of Cameron lesions: Medical or surgical, which should be individualized for each patient. The patients that were treated with a spectrum of medical therapy and who have had long-term follow-up, about one third have had a recurrence of the lesion and $17 \%$ (8/48) have developed complications, most commonly either acute upper $\mathrm{Gl}$ bleeding $(6.3 \%)$ or persistent and recurrent iron deficiency anemia (8.3\%). ${ }^{1}$ Endoscopic management for Cameron ulcer with active bleeding has been described by Lin et al. using band ligation [10], [11].

\section{Conclusion}

Upper $\mathrm{Gl}$ endoscopy is a gold standard of diagnostic modality. This proves that there were no other lesions responsible for blood loss.

\section{References}

1. Weston AP. Hiatal hernia with Cameron ulcers and erosions. Gastrointest Endosc Clin N Am 1996;6(4):671-9.

PMid:8899401

2. Cameron AJ, Higgins JA. Linear gastric erosion. A lesion associated with large diaphragmatic hernia and chronic blood loss anemia. Gastroenterology. 1986;91(2):338-42.

PMid:3487479

3. Maganty K, Smith RL. Cameron lesions: Unusual cause of gastrointestinal bleeding and anemia. Digestion. 2008;77(3- 4):214-7. http://doi.org/10.1159/000144281

PMid:18622137
4. Moskovitz M, Fadden R, Min T, Jansma D, Gavaler J. Large hiatal hernias, anemia, and linear gastric erosion: Studies of etiology and medical therapy. Am J Gastroenterol. 1992;87(5):622-6.

PMid:1595651

5. Nguyen N, Tam W, Kimber R, Roberts -Thomson IC, Gastrointestinal: Camron's erosions. J Gastroenterol Hepatol. 2000.

PMid:11982707

6. Zaman A, Katon RM. Push enteroscopy for obscure gastrointestinal bleeding yields a high incidence of proximal lesions within reach of a standard endoscope. Gastrointest Endosc. 1998;47(5):372-6. http://doi.org/10.1016/ s0016-5107(98)70221-4 PMid:9609429

7. Gray DM, Kushnir V, Kalra G, Rosenstock A, Alsakka MA Patel A, et al. Cameron lesions in patients with hiatal hernias: Prevalence, presentation, and treatment outcome. Dis Esophagus. 2015;28(5):448-52. https://doi.org/10.1111/ dote. 12223

PMid:24758713

8. Camus M, Jensen DM, Ohning GV, Kovacs TO, Ghassemi KA Jutabha $\mathrm{R}$, et al. Severe upper gastrointestinal hemorrhage from linear gastric ulcers in large hiatal hernias: A large prospective case series of Cameron ulcers. Endoscopy. 2013;45(5):397- 400. http://doi.org/10.1055/s-0032-1326294. PMid:23616128

9. Sehested TSG, Carlson N, Hansen PW, Gerds TA, Charlot MG Torp-Pedersen C, et al. Reduced risk of gastrointestinal bleeding associated with proton pump inhibitor in patients treated with dual antiplatelet therapy after myocardial infarction. Eur Heart J. 2019;40(24):193-1970.

PMid:30851041

10. Tjwa ET, Holster IL, Kuipers EJ. Endoscopic management of nonvariceal, nonulcer upper gastrointestinal bleeding. Gastroenterol Clin North Am 2014;43:707-19. http://doi. org/10.1016/j.gtc.2014.08.004 PMid:25440920

11. Lin CC, Chen TH, Ho WC, Chen TY. Endoscopic treatment of a Cameron lesion presenting as life-threatening gastrointestinal hemorrhage. J Clin Gastroenterol. 2001;33(5):423-4. http://doi. org/10.1097/00004836-200111000-00018

PMid:11606864 